\title{
PRIMARY CARCINOMA OF THE PANCREAS IN AN INFANT AGED SEVEN MONTHS
}

\author{
BY \\ BERYL D. CORNER, M.D., M.R.C.P. \\ Physician to Out-Patients, Bristol Children's Hospital
}

Primary malignant disease of the pancreas in infancy and childhood is a rarity as indicated by the few cases reported in the literature.

Lymphosarcoma was found in a new-born infant by L'Huillier (1904), and in a girl aged four years by Litten (quoted by Ewing, 1928). Todd (1818) reported a case of a girl aged fourteen years, who having been ill for some months with pyrexia and digestive disturbances, became deeply jaundiced and died. Post mortem, the pancreas appeared scirrhous, and the head of the gland was converted into a solid tumour mass which obstructed the common bile duct, causing gross distension of biliary and hepatic ducts. Rokitansky (1842) and Wedl (1866) both describe a scirrhous condition of the pancreas in new-born infants, but in Wedl's case the mother had syphilis, so that the condition was probably syphilitic and not malignant. Battersby (1844) reports a case of carcinoma in a fourteen-year-old child, and Herringham (1894) in a two-year-old child, but no details of the case are given and in none of these five cases is there any histological confirmation of malignancy.

There are five recorded cases of pancreatic primary carcinoma in childhood in which histological evidence of malignancy has keen obtained. Bohn's case (1885) was an infant aged six months who was found to have an abdominal tumour and developed jaundice six weeks before death. Microscopy of the tumour, which was situated in the head of the pancreas, showed that it had a finely meshed alveolar structure in the spaces of which were clusters of medium-sized cubical epithelial cells. There were secondary deposits in the liver and in the glands at the portal fissure.

Kühn (1887) reported a case in a girl aged two years. This child had been ill for about nine months and then developed oedema of her legs and diarrhoea. An enlargement of the liver was found and she died from pneumonia. Post mortem the pancreas was found to be almost completely replaced by a reddish tumour, and there were secondary nodules in the liver. Histology showed that the tumour was a cylindrical celled adeno-carcinoma. Simon's (1889) case was a thirteen-year-old boy, whose symptoms were anorexia and diarrhoea with jaundice eight weeks before death. The whole gland with the exception of a small part of the tail, was involved in a tumour mass, the histology of which was identical with Kühn's case. Bandelier (1896) reports a similar case. Stewart and Stewart
(1915) had a case in a nine-year-old boy, in whom pain, anorexia and constipation followed a blow on the abdomen. The child was well-nourished and the only abnormal clinical finding was an irregular mass situated in the left upper abdomen. At operation a tumour of the tail of the pancreas was revealed, the rest of the gland being hard and irregular. A few reddish lymph nodes were seen along the upper border of the pancreas, but there was no other evidence of secondary involvement in the abdomen. Only partial autopsy was performed but microscopically the tumour was found to have a fibrous tissue framework occupied by islets of closely packed cells showing mitotic figures and necrosis. The tumour was named medullary carcinoma of the pancreas.

The following case is reported in view of the early age of the patient, and the scarcity of reports of this condition in childhood in the English literature.

\section{Case report}

History. Betty A. was a full-time baby, born by normal delivery on February 26, 1939. Both parents were healthy, and she had a sister aged two years who was alive and well. She was breast-fed for three months and then weaned on to a cows' milk and water mixture. Her abdomen had seemed large since birth, but at the age of five months the mother complained that it was increasing rapidly in size and seemed very hard. Bowels were usually constipated, appetite was good but the child had always had a good deal of flatulence and magnesia was given regularly. She was admitted to Bristol Children's Hospital on October 19, 1939, because she had been screaming continuously for three days and had vomited once.

EXAMINATION. This revealed an extremely distressed-looking infant, who was well-nourished but very pale. There was no clinical evidence of jaundice or oedema. Weight, $18 \mathrm{lb} .8 \mathrm{oz}$. Temperature $100 \cdot 6^{\circ} \mathrm{F}$., pulse 160 , respiration, 56 .

ABDOMEN. This appeared distended with numerous dilated superficial veins. A tumour filled the upper part, extending to the level of the umbilicus on the right, and into the iliac fossa on the left. The lower border of the mass was sharply notched at the level of the umbilicus, and the surface was smooth, except the left lower portion which was definitely nodular. The tumour was typically an enlarged liver. A little free fluid was detected. 


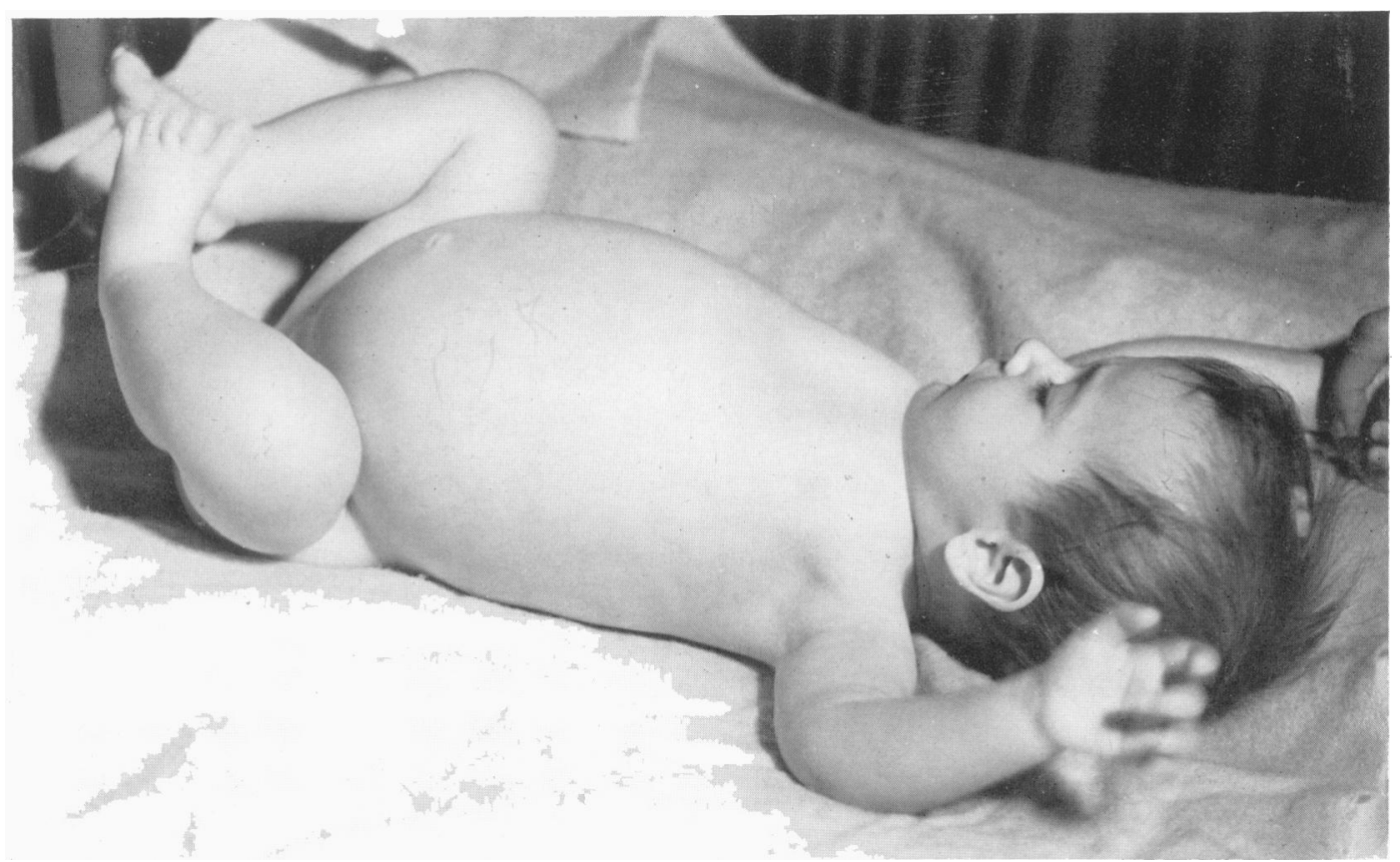

Fig. 1.-Betty A. Six days before death. Aged seven months. Note good state of nutrition.

URINE was acid, and contained sugar, but no urobilin or other abnormalities.

INVESTIGATIONS. Wassermann reaction, negative.

Blood count. Haemoglobin 40 per cent., red corpuscles, 3,270,000 per c.mm., average red cell diameter, $7 \cdot 5 \mu$, white corpuscles, 15,500 per c.mm. polymorphonuclears, 53 per cent., lymphocytes, 38 per cent., monocytes, 9 per cent. Anisocytosis and poikilocytosis marked, and many ring forms. Van den Bergh reaction: direct slight positive, indirect 0.9 unit.

Blood sugar. (Fasting) $113.2 \mathrm{mgm}$. per cent.

Blood urea. $14.4 \mathrm{mgm}$. per cent.

Blood cholesterol. $109 \mathrm{mgm}$. per cent. Blood groups of child and parents $O$.

Progress. The child remained febrile, temperature varying from 100 to $100 \cdot 6^{\circ}$ F.; she sweated profusely and cried continuously as if in pain. Seven-ounce milk feeds were taken well without vomiting, and there were two relaxed green stools daily.

Eight days after admission, she was given a blood transfusion and laparotomy was performed under general anaesthesia by $\mathrm{Mr}$. Wilfrid Adams. A greatly enlarged liver was found which contained a greyish nodular mass in the left lobe, and numerous other nodules could aiso be seen. A portion of the nodular mass was excised for biopsy, but owing to the infant's poor condition, the abdomen was closed without further exploration. Death occurred two hours after operation.

BIOPSY REPORT. Pocrly differentiated adenocarcincma. Cells are small with scanty cytoplasm and do not resemble liver cells or bile-duct epithelium.

AUTOPSY RFPORT. (Autopsy performed eighteen hours after death by Professor T. F. Hewer.) The body was that of a well nourished female infant with a distended abdomen but no jaundice or other ex- ternal sign of disease. A recent exploratory laparotomy wound accounted for the presence of a little blood in the abdominal cavity. The liver was greatly enlarged, weighing 1,680 gm. Its width was $22 \mathrm{~cm}$.; its greatest thickness antero-posteriorly was $7 \mathrm{~cm}$. The surface of the liver was regular and rounded on the right side but just to the left of the falciform ligament, the margin turned sharply downwards along a massive lobe of tumour, which accounted for the greater depth of the liver on this side. In the hilum of the liver there were several large lymph glands which were full of necrotic tumour. The gall-bladder and bile dicts were healthy and patent. On section the whole liver was invaded by an irregular yellowish mass of tumour which was necrotic in the centre and contained one area of recent haemorrhage. The liver was not jaundiced. The lymph nodes in the hilum of the liver, alongside the common bile duct and around the head of the pancreas were full of tumour. A large mass of firm tumour was present in the head of the pancreas. Metastases were found in the anterior mediastinal lymph nodes and studded all over the pleural surfaces of both lungs. No tumour was found elsewhere, and the rest of the alimentary tract from mouth to anus appeared healthy.

Histologically the tumour in the head of the pancreas (fig. 2) consisted of a cylindrical cell adenocarcinoma apparently derived from ducts. It had produced some fibrous tissue reaction. The adjacent pancreatic acini did not appear abnormal and there was no sign of obstruction of pancreatic ducts or of disease in the body or tail of the pancreas. The metastases in lymph nodes, liver and lung were less well differentiated and had not produced a scirrhous reaction. The liver tissue alongside the tumour was not cirrhotic and there was no bile duct dilatation. Many branches of the portal vein were full of tumour. 


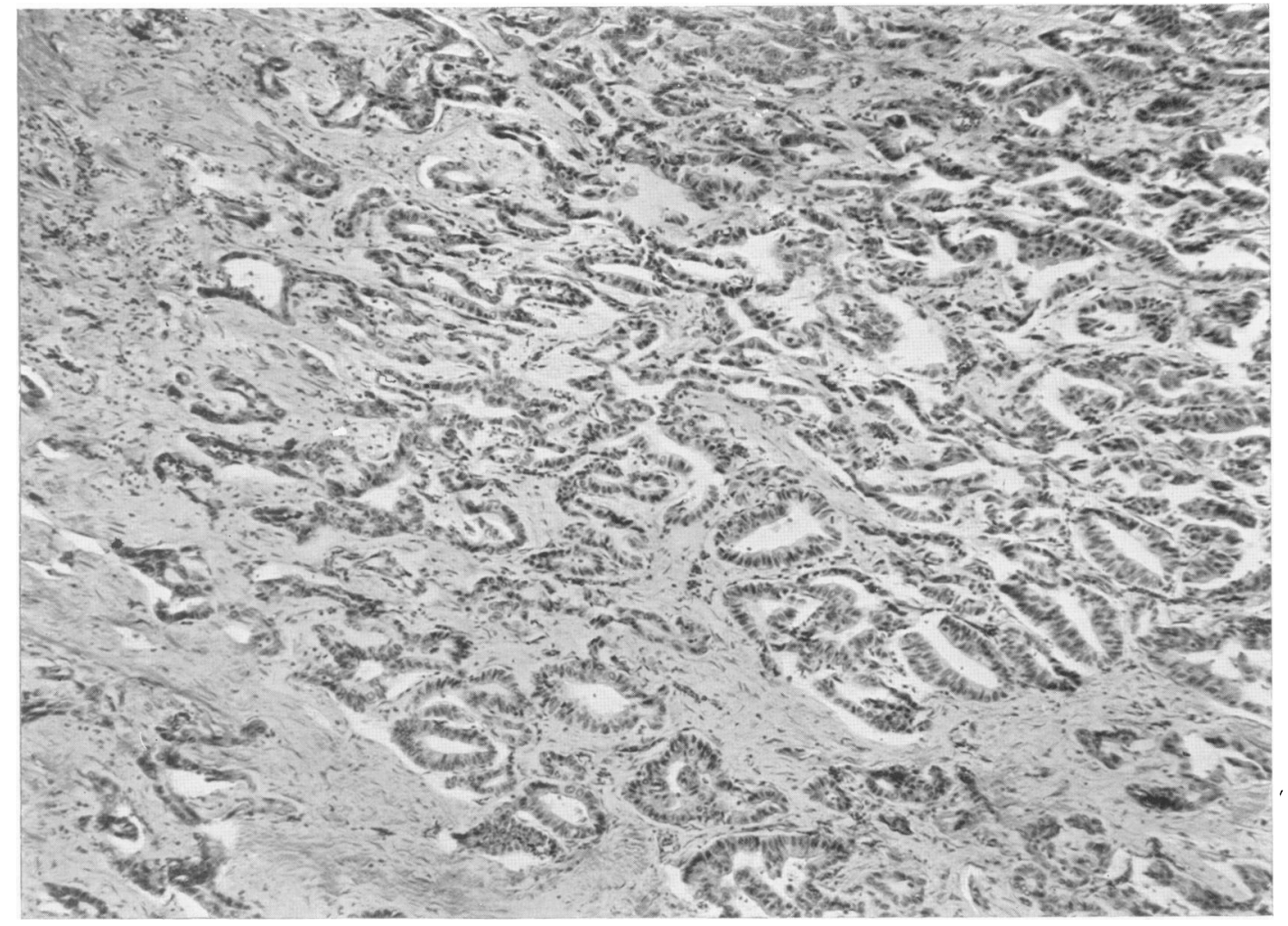

FIG. 2.-Photomicrograph of section through tumour in head of pancreas.

\section{Discussion}

The commonest clinical features found in cases of pancreatic carcinoma are cachexia, anorexia and other digestive disturbances, jaundice and a palpable abdominal tumour. In this case the outstanding clinical signs were the abdominal tumour and severe anaemia; the absence of any wasting (see fig. 1) and good appetite were notable. Glycosuria, which was present in this case, was found in forty-three out of two hundred and one cases at all ages collected from various authors by Kiefer (1927); it was not noted in any of the other cases referred to in children. The duration of the disease in the other childhood cases has been described as several months, most of the cases only being under observation for the last few weeks; in this case the history would indicate that there was definite hepatic enlargement at the age of five months, and therefore the primary growth probably arose shortly after birth. Bohn's case (1885) is the only other case of definitely established pancreatic carcinoma that has been reported in an infant under two years old.

The differential diagnosis lay between carcinoma of the pancreas and carcinoma of the intra-hepatic bile ducts. The former diagnosis may be accepted since the tumour in the pancreas was better differentiated than that in the liver, and closely resembled a moderately scirrhous carcinoma derived from the pancreatic ducts, whilst there was no indication of the biliary obstruction in the liver that is usually associated with malignant cholangioma. Evidence of spread of the tumour within the branches of the portal vein also favours a pancreatic origin.

Thanks are due to Professor Hewer for the autopsy report on this case, and for the photographs.

\section{REFERENCES}

Battersby, F. (1844). Gaz. méd. Paris, 12, 617.

Bandelier, B. (1896). Dissert. Greifswald, 21.

Böhn (1885). Jb. Kinderheilk., 23, 144.

Herringham, W. P. (1894). St. Bart.'s Hosp. med. Rep., 30, 5 .

Kiefer, E. D. (1927). Arch. intern. Med., 40, 1.

Kühn, A. (1887). Berl. klin. Wschr., 24, 494.

L'Huillier, A. (1904). Virchows Arch., 178, 507.

Litten, M. quoted by Ewing, J. (1928). Neoplastic Diseases, Phila. and Lond., third ed., 749.

Rokitansky, C. (1842). Handbuch der pathologischen Anatomie, Wien, 3, 397.

Simon, M. (1889). Dissert. Greifswald.

Stewart, S. C., and Stewart, L. F. (1915). Int. Clin., 2, 118.

Todd, C. H. (1818). Dublin Hosp. Rep., 1, 325.

Wedl, C. (1866). Wien. med. Wschr., 16, 943. 